\title{
A STUDY TO CORRELATE HBA1C LEVELS AND LEFT VENTRICULAR DIASTOLIC DYSFUNCTION IN NEWLY DIAGNOSED TYPE II DIABETES MELLITUS
}

\author{
Vasanthi Perumal', Namitha Narayanan², Jayanthi Rangarajan³, Elangumanan Palanisamy4, Mohamed Kalifa ${ }^{5}$, Uma Maheshwari \\ Perincheri6, Pravin Selvam Selvaraj ${ }^{7}$, Santhi Chinnathambi ${ }^{8}$

\begin{abstract}
${ }^{1}$ Associate Professor, Department of Internal Medicine, Govt. Stanley Medical College \& Hospital, Chennai. ${ }^{2}$ Assistant Professor, Department of Internal Medicine, Govt. Stanley Medical College \& Hospital, Chennai. 3 Professor, Department of Internal Medicine, Govt. Stanley Medical College \& Hospital, Chennai. 4Junior Resident, Department of Internal Medicine, Govt. Stanley Medical College \& Hospital, Chennai. ${ }^{5}$ Assistant Professor, Department of Internal Medicine, Govt. Stanley Medical College \& Hospital, Chennai. 6Junior Resident, Department of Internal Medicine, Govt. Stanley Medical College \& Hospital, Chennai. 7 Junior Resident, Department of Internal Medicine, Govt. Stanley Medical College \& Hospital, Chennai. 8Junior Resident, Department of Internal Medicine, Govt. Stanley Medical College \& Hospital, Chennai.
\end{abstract}

\section{ABSTRACT}

\section{AIM}

To assess the correlation of HBA1C levels with left ventricular diastolic dysfunction in newly diagnosed Type 2 diabetic patient. This prospective study was done at Department of General Medicine, OPD, Medical Wards, Stanley Medical College and Hospital, Chennai.

\section{RESULT}

The mean HBA1C levels were meaningfully more in Left Ventricular Diastolic Dysfunction (LVDD) positive group compared to the LVDD negative group by $1.33 \%$. This significant difference of $15 \%$ increase in mean HBA1C levels in LVDD positive group compared to the LVDD negative group is true and has not occurred by chance.

\section{CONCLUSION}

One-fifth to one-third of diabetic patients will develop LVDD. Patients with HBA1C (8 to 10) have double the chances to develop LVDD than with HbA1c 6.5 to 8. Patients with HBA1C more than 10 have five times the chances to develop LVDD than with HbA1C 6.5 to 8. Patients with HBA1C more than 10 have three times the chances to develop LVDD than with HBA1C 8 to 10 . One-fourth to one-half of diabetic patients will develop LVDD grade 1. Patients with HBA1C 8 to 10 have double the chances to develop LVDD grade 1 than with HBA1C 6.5 to 8. Patients with HBA1C more than 10 have four times the chances to develop LVDD grade 1 than with HBA1C 6.5 to 8. Patients with HBA1C more than 10 have two times the chances to develop LVDD than with HBA1C 8 to 10.

\section{KEYWORDS}

Type 2 Diabetes, Left Ventricular Diastolic Dysfunction, HbA1C.

HOW TO CITE THIS ARTICLE: Perumal V, Narayanan N, Rangarajan J, et al. A study to correlate HbA1C levels and left ventricular diastolic dysfunction in newly diagnosed type II diabetes mellitus. J. Evolution Med. Dent. Sci. 2016;5(51):3312-3317, DOI: $10.14260 /$ jemds/2016/767

\section{INTRODUCTION}

Diabetes mellitus is one of the most common diseases in the world and is acquiring epidemic proportions. Its prevalence is growing in both developed and developing countries. Globally and nationally, diabetes and its complications has become the most important contemporary and challenging health problem. Compared to other races, Indians are genetically more susceptible. Diabetes is one such important metabolic disease, which affects nearly every organ system in the body. The main cause of morbidity and mortality in diabetic patients is due to cardiac complications. It has been estimated that by the year 2025, 300 million individuals would be affected with diabetes all over the world. In India, it is estimated that presently 19.4 million individuals are affected by this deadly

Financial or Other, Competing Interest: None.

Submission 05-05-2016, Peer Review 04-06-2016,

Acceptance 10-06-2016, Published 27-06-2016.

Corresponding Author:

Vasanthi Perumal,

36, Sunkuvar Street,

Triplicane,

Chennai - 600005 .

E-mail:medipubs@gmail.com

DOI: $10.14260 /$ jemds/2016/767 disease, which is likely to go up to 57.2 million by the year 2025.

Although, the prevalence of both Type 1 and Type 2 DM is increasing worldwide, the prevalence of Type $2 \mathrm{DM}$ is on the rise much more rapidly, which is due to increasing obesity and reduced activity levels.[1]

Diabetic individuals have been reported to develop congestive heart failure in the absence of coronary heart disease, hypertension or any structural heart disease. ${ }^{[2]}$ The term "Diabetic Cardiomyopathy" has been introduced for this condition. The existence of a diabetic cardiomyopathy was first proposed by Rubler in 1972.[3][4]

\section{Diabetic Cardiomyopathy}

In India Tripathy reported in 1973, the existence of cardiac enlargement and failure in diabetes without obvious coronary artery disease, hypertension or structural heart disease suggesting a specific entity - Diabetic cardiomyopathy.

\section{Pathogenesis}

The proposed mechanisms responsible for development of diabetic cardiomyopathy are: 


\section{Hyperglycaemia}

It affects contractility of heart by two main mechanisms,

1. Production of advanced glycation end products. [5]

2. Production of free radicals.

Myocardial fibrosis results from elevated collagen deposition in myocardium; this is a result of over-production of reactive oxygen species from the above mechanisms.

\section{Free Fatty Acids}

Increased free fatty acids are associated with activation of proliferation activated receptor alpha (PPAR alpha), which promote mitochondrial uncoupling of oxidative phosphorylation and reduces myocardial high energy reserves.[6] These mechanisms are responsible for cardiac dysfunction.

\section{Protein Kinase C}

The levels of protein kinase $\mathrm{C}$ are elevated in diabetic patients. It reduces the levels of nitric oxide and increases the production of free radicals. These sequential changes lead to dysfunction of the endothelium. ${ }^{[7]}$

\section{Renin Angiotensin and Aldosterone Mechanism}

In concomitant hyperglycaemia, the RAAS mechanism gets dysregulated and both aldosterone and glucose stimulate growth of myofibroblast leading to myocardial fibrosis.[8]

\section{Vascular Endothelial Growth Factor (VEGF)}

In diabetics the vascular endothelial growth factors levels are reduced, which is responsible for angiogenesis and collateral formation in cardiac ischaemia.[9]

\section{Autonomic Neuropathy}

In cardiac autonomic neuropathy, the loss of parasympathetic activity results in relative predominance over sympathetic activity in the sympathovagal balance. The sympathetic overactivity stimulates renin angiotensin-aldosterone-adrenergic system which increases the heart rate, stroke volume and peripheral resistance. The sympathetic over-activity with myocardial sympathetic denervation leads to impairment of coronary vasodilator reserve, impaired ventricular diastolic filling and diastolic dysfunction.

\author{
Risk Factors \\ - Chronic high blood sugar level. \\ - Obesity. \\ - Hypertension. \\ - Dyslipidaemia. \\ - Smoking. \\ - Alcoholism. \\ - Sedentary lifestyle.
}

\section{Clinical Features}

Diabetic cardiomyopathy is a progressive state initially with myocardial diastolic dysfunction, later on systolic dysfunction supervenes with classical features of CCF. Patient has no symptoms in early stage, later progresses to fatigue, weakness, effort intolerance, shortness of breath with cough, swelling of the feet. Cardiomegaly, atrial and ventricular gallop, pulmonary congestion is frequent.

\section{STAGING OF DIABETIC CARDIOMYOPATHY}

\section{Stage 1}

It includes diastolic heart failure with preserved ejection fraction with hypertrophy without hypertension.

\section{Stage 2}

Diastolic and systolic heart failure with dilatation and reduced ejection fraction without hypertension.

\section{Stage 3}

Systolic and diastolic heart failure with microvascular disease and hypertension without CAD.

Stage 4

Heart failure associated with ischaemia/infarction.

\section{DIAGNOSIS}

\section{Evaluation of Left Ventricular Function}

There are two chief methods of evaluating the LV function.

\author{
Non-Invasive Methods Include \\ a. Echocardiography and Cardiac Doppler. \\ b. Systolic Time Intervals (STI). \\ c. Apex Cardiography (ACG). \\ d. Gadolinium-enhanced cardiac MRI.
}

\section{Invasive Method}

Cardiac catheterization.

\section{Doppler Echocardiography}

This is an inexpensive tool to detect the functional and structural cardiac anomaly.

Trans-mitral Doppler is a very useful method in diagnosis of left ventricular diastolic dysfunction. The variables commonly measured are early ventricular filling (E), late ventricular filling wave $(\mathrm{A})$ and $\mathrm{E} / \mathrm{A}$ ratio, Isovolumetric Relaxation Time (IVRT), Deceleration Time (DT), velocity at the mitral annulus level during early ventricular filling (e'). LV diastolic dysfunction was considered to any one of the following findings.

E/A ratio $<1$ or $>2$

DT $<150$ OR $>220 \mathrm{~ms}$

IVRT $<60$ OR $>100 \mathrm{~ms}$

E/e' ratio $>15$ (Ratio of mitral peak velocity of early filling (E) to early diastolic mitral annular velocity ( $\left.\mathrm{e}^{\prime}\right)$.

\section{ECHOCARDIOGRAPHIC GRADING OF DIASTOLIC DYSFUNCTION.[10] \\ Grade I}

Abnormal relaxation pattern.

Reversal of E/A ratio

IVRT $>100 \mathrm{~ms}$

DT $>240 \mathrm{~ms}$

E caused by accumulation of blood in the atria during previous systole.

A caused by atrial contraction.

\section{Grade II}

Pseudonormal filling pattern.

Elevated atrial filling pressure.

E/A ratio return to range of 0.8 to 1.5 .

IVRT $<90 \mathrm{~ms}$.

DT $<160 \mathrm{~ms}$. 


\section{Grade III}

Reversible restrictive pattern.

Reversal of diastolic abnormalities on Valsalva manoeuvre.

E/A ratio $>2$.

IVRT $<80 \mathrm{~ms}$.

DT $<160$ ms.

\section{Grade IV}

Fixed restrictive pattern.

Most severe form of diastolic dysfunction.

No reversibility of diastolic abnormalities on Valsalva manoeuvre.

E/A ratio $>2$.

\section{Gadolinium Enhanced MRI}

It is used to assess the myocardial flow reserve and myocardial perfusion and fibrosis. Cardiac MRI diagnosed myocardial scar without evidence of myocardial infarction. It is a non-invasive technique to assess the left ventricular function and size.

\section{Invasive Studies}

Cardiac catheterisation

Elevated Left Ventricular End Diastolic Pressure (LVEDP) >16 mmHg.

Mean pulmonary capillary wedge pressure $>12 \mathrm{mmHg}$ Normal coronary angiogram is suggestive of diabetic cardiomyopathy.

\section{AIM AND OBJECTIVES}

To assess the correlation of HBA1C levels with Left Ventricular Diastolic Dysfunction (LVDD) in newly diagnosed Type 2 diabetic patient.

\section{MATERIALS AND METHOD}

Place of Study

Department of General Medicine, OPD, Medical wards.

Stanley Medical College and Hospital, Chennai.

\section{Study Population}

100 consecutive patients of newly diagnosed Type 2 diabetes mellitus.

\section{Study Design \\ Prospective study.}

\section{Ethical Committee Approval}

Ethical committee approval was obtained for the study.

\section{Study Period}

March to September 2015.

\section{Diagnostic Criteria (American Diabetes Association).[11]} FBS $\geq 126 \mathrm{mg} / \mathrm{dL}$.

$2 \mathrm{hr}$. plasma glucose $\geq 200 \mathrm{mg} / \mathrm{dL}$ during an OGTT.

RBS $\geq 200 \mathrm{mg} / \mathrm{dL}$ with symptoms (polyuria, polydipsia, polyphagia, weight loss).

$\mathrm{HbA} 1 \mathrm{C}>6.5 \%$.

\section{Left Ventricular Diastolic Dysfunction}

Reduction in peak velocity of early mitral flow (E) increase over peak velocity of late mitral flow (A) with E/A ratio of $<1$ and increase in Left Atrial (LA) size with preserved ejection fraction were considered as the evidence of left ventricular diastolic dysfunction.

\section{Inclusion Criteria}

All newly diagnosed Type 2 diabetes mellitus patients, who clinically had no cardiovascular symptoms and blood pressure of $<130 / 80 \mathrm{mmHg}$ with normal ECG.

\section{Exclusion Criteria}

- Known diabetic patients on insulin and OHA.

- Ischaemic heart disease.

- Hypertensive heart disease.

- Congestive heart failure.

- Valvular heart disease.

- Cardiomyopathy.

- Connective tissue diseases.

- Renal failure.

- Thyroid dysfunction were excluded from the study.

\section{METHODOLOGY}

Patients with newly diagnosed Type 2 diabetes presenting to the Medicine Outpatient Service and those admitted to the medical wards at Stanley Medical College Hospital, Chennai, were included in the present study. Informed consent was obtained from the subjects. Detailed medical history was collected from each patient. Patients were subjected for clinical examination followed by relevant investigations.

\section{The Patients Underwent the following Investigations}

a. FBS, PPBS.

b. Glycosylated haemoglobin (HbA1c).

c. Urea, creatinine.

d. Fasting lipid profile.

e. Urine routine.

f. ECG.

g. Doppler Echo was done in each patient and 3-4 cardiac cycles were analysed to get best phase for better outcome of results.

In Doppler Echo Study following Values Were Evaluated

1. E-peak velocity of early mitral flow (N: $50-90 \mathrm{~cm} / \mathrm{sec}$ ).

2. A-peak velocity of late mitral flow (N: $30-70 \mathrm{~cm} / \mathrm{sec}$ ).

3. E/A ratio (N: 1-2).

4. Left atrial size (N: $3-4 \mathrm{cms})$.

5. $\mathrm{EF}(\mathrm{N}:>60 \%)$.

Reduction in E velocity increase over A velocity with E/A ratio of $<1$ and increase in left atrial (LA) size with preserved Ejection Fraction (EF) were considered as the evidence of left ventricular diastolic dysfunction.

\section{Human Subject Protection}

The full protocol along with draft questionnaire and Informed consent was kept in Institutional Ethical Committee and approval was obtained.

\section{Informed Consent}

Consent form was written in both English and Tamil and consent was obtained from the participant, confidentiality was maintained. 
Descriptive statistics was done for all data and were reported in terms of mean values and percentages. Suitable statistical tests of comparison were done. Continuous variables were analysed with the unpaired ' $t$ ' test. Categorical variables were analysed with the Chi-Square Test and Fisher Exact Test. Statistical significance was taken as $\mathrm{P}<0.05$. The data was analysed using SPSS version 16 and Microsoft Excel 2007.

\section{RESULTS}

\begin{tabular}{|c|c|c|}
\hline SEX & Index & Frequency \\
\hline & Female & 44 \\
\hline & Male & 56 \\
\hline AGE & Sex & mean age \\
\hline & Femall & 45.23 \\
\hline & Male & 44.9 \\
\hline & Female without LVDD & 45.48 \\
\hline & Male without LVDD & 43.89 \\
\hline & Female with LVDD & 44.02 \\
\hline & Male with LVDD & 47.86 \\
\hline \multicolumn{2}{|c|}{ Table 1: Age and Sex Distribution of LVDD } \\
\hline
\end{tabular}

\begin{tabular}{|c|c|c|}
\hline LVDD (Both Gr1 \& Gr2) & Frequency & Frequency \\
\hline & yes & No \\
\hline All & 37 & 63 \\
\hline Female & 15 & 29 \\
\hline Male & 22 & 34 \\
\hline \multirow[t]{2}{*}{ LVDD Grade 1 only } & Frequency & Frequency \\
\hline & yes & No \\
\hline All & 33 & 67 \\
\hline Female & 14 & 30 \\
\hline Male & 19 & 37 \\
\hline \multirow[t]{2}{*}{ LVDD Grade 2 only } & Frequency & Frequency \\
\hline & yes & No \\
\hline All & 4 & 96 \\
\hline Female & 1 & 43 \\
\hline Male & 3 & 53 \\
\hline \multicolumn{3}{|c|}{$\begin{array}{c}\text { Table 2: Sex Distribution of LVDD, } \\
\text { LVDD Grade } 1 \text { and Grade } 2\end{array}$} \\
\hline
\end{tabular}

\begin{tabular}{|c|c|c|c|}
\hline & \multicolumn{2}{|c|}{ LVDD } & \\
\hline Age Group & No & Yes & Total \\
\hline 31 to 40 years & 20 & 7 & 27 \\
\hline 41 to 50 years & 34 & 19 & 53 \\
\hline 51 to 60 years & 9 & 11 & 20 \\
\hline Total & $\mathbf{6 3}$ & $\mathbf{3 7}$ & $\mathbf{1 0 0}$ \\
\hline Table 3: Age Group Wise Distribution of LVDD \\
\hline
\end{tabular}

\begin{tabular}{|c|c|}
\hline Sex & Mean Age \\
\hline All & 46.57 \\
\hline Female without LVDD grade 1 & 44.4 \\
\hline Male without LVDD grade 1 & 44.7 \\
\hline Female with LVDD grade 1 & 46 \\
\hline Male with LVDD grade 1 & 47 \\
\hline \multicolumn{2}{|c|}{ Table 4: Sex and Mean Age Distribution of LVDD Grade } \\
\hline
\end{tabular}

\begin{tabular}{|c|c|c|c|}
\hline & \multicolumn{2}{|c|}{ LVDD Grade 1} & \\
\hline Age Group & No & Yes & Total \\
\hline 31 to 40 years & 20 & 7 & 27 \\
\hline 41 to 50 years & 35 & 18 & 53 \\
\hline 51 to 60 years & 12 & 8 & 20 \\
\hline Total & 67 & 33 & 100 \\
\hline
\end{tabular}

\begin{tabular}{|c|c|c|}
\hline Age & Sex & Mean Age \\
\hline & All & 54 \\
\hline & Female without LVDD grade 2 & 44.58 \\
\hline & Male without LVDD grade 2 & 45.09 \\
\hline & Female with LVDD grade 2 & 59 \\
\hline & Male with LVDD grade 2 & 52.33 \\
\hline
\end{tabular}

\begin{tabular}{|c|c|c|c|}
\hline & \multicolumn{2}{|c|}{ LVDD Grade 2} & \\
\hline Age Group & No & Yes & Total \\
\hline 31 to 40 years & 27 & 0 & 27 \\
\hline 41 to 50 years & 52 & 1 & 53 \\
\hline 51 to 60 years & 17 & 3 & 20 \\
\hline Total & 96 & 4 & 100 \\
\hline
\end{tabular}

\begin{tabular}{|c|c|c|c|c|}
\hline LVDD & Odds Ratio & P-value & $\begin{array}{c}\text { Females } \\
\text { Odds Ratio } \\
\text { (P value) }\end{array}$ & $\begin{array}{c}\text { Males } \\
\text { Odds } \\
\text { Ratio } \\
\text { (P value) }\end{array}$ \\
\hline HBA1C 6.5 to 8 & 0.17 & 0.035 & $1(\mathrm{NA})$ & $0.36(0.27)$ \\
\hline HBA1C 8 to 10 & 0.3541667 & 0.021 & $0.157(0.01)$ & $0.64(0.46)$ \\
\hline HBA1C >10 & 1 & NA & $1(\mathrm{NA})$ & $1(\mathrm{NA})$ \\
\hline \multicolumn{2}{|c|}{$\begin{array}{r}\text { Table 8: Odds Ratio with Multi-Nominal Logistic } \\
\text { Regression for HBA1C Levels with LVDD }\end{array}$} \\
\end{tabular}

\begin{tabular}{|c|c|c|c|c|}
\hline LVDD GR1 & Odds Ratio & P-value & $\begin{array}{c}\text { Females } \\
\text { Odds Ratio } \\
\text { (P value) }\end{array}$ & $\begin{array}{c}\text { Males } \\
\text { Odds } \\
\text { Ratio } \\
\text { (P value) }\end{array}$ \\
\hline HBA1C65to8 & 0.2625 & 0.112 & $1(\mathrm{NA})$ & $0.66(0.66)$ \\
\hline HBA1C8to10 & 0.54 & 0.182 & $0.204(0.02)$ & $1.17(0.79)$ \\
\hline HBA1C10 & 1 & $\mathrm{NA}$ & $1(\mathrm{NA})$ & $1(\mathrm{NA})$ \\
\hline \multicolumn{3}{|c|}{ Table 9: Odds Ratio with Multi-Nominal } \\
Logistic Regression for HBA1C Levels with LVDD Grade 1 \\
\hline
\end{tabular}

\begin{tabular}{|c|c|c|}
\hline LVDD & Odds Ratio & P-value \\
\hline Age 31 to 40 & 0.286 & 0.047 \\
\hline Age 41 to 50 & 0.457 & 0.142 \\
\hline Age 51 to 60 & 1 & NA \\
\hline \multicolumn{2}{|c|}{ Table10: Odds Ratio with Multi-Nominal Logistic } \\
Regression for LVDD with Age Groups \\
\hline
\end{tabular}

\begin{tabular}{|c|c|c|}
\hline LVDD Grade 1 & Odds Ratio & P-value \\
\hline Age 31 to 40 & 0.525 & 0.309 \\
\hline Age 41 to 50 & 0.771 & 0.631 \\
\hline Age 51 to 60 & 1 & NA \\
\hline \multicolumn{2}{|c|}{ Table 11: Odds Ratio with Multi-Nominal Logistic } \\
Regression for LVDD Grade 1 with Age Groups \\
\hline
\end{tabular}

Patients with age group 31 to 40 have $52 \%$ chances to get LVDD grade 1 without significant $P$ value of 0.309 . Patients with age between 31 to 40 have $77 \%$ chances to get LVDD without significant $P$ value of 0.631 .

\section{DISCUSSION}

Patients with $\mathrm{HbA} 1 \mathrm{c}$ between 6.5 to 8 have $17 \%$ chances to get LVDD with significant $P$ value of 0.03 . Patients with HbA1c between 8 to 10 have $35 \%$ chances to get LVDD with significant $P$ value of 0.02 . Patients with HbA1c 6.5 to 8 have double the chances when compared to HbA1c 6.5 to 8 with significant association statistically. Female patients with HbA1c 8 to 10 have 15\% chances of having LVDD with significant association statistically $(P$ value 0.02$)$. Male patients with $\mathrm{HbA1c}$ between 6.5 to 8 have $36 \%$ chances to get LVDD without significant $P$ value of 0.279 . Male patients with 
HbA1c of 8 to 10 have $64 \%$ chances to get LVDD without significant $P$ value of 0.46 .

Patents with $\mathrm{HbA1c}$ between 6.5 to 8 have $26 \%$ chances to get LVDD Grade 1 without significant $P$ value of 0.112 . Patients with $\mathrm{HbA1c}$ of 8 to 10 have $54 \%$ chances to get LVDD grade 1 without significant $P$ value of 0.182 . Patients with $\mathrm{HbA1c} 6.5$ to 8 have double the chances when compared to HbA1c 6.5 to 8 without significant association statistically. Female patients with $\mathrm{HbA1c} 8$ to 10 have $20 \%$ chances of having LVDD grade 1 with significant association statistically ( $P$ value 0.02 ). Male patients with $\mathrm{HbA1c}$ between 6.5 to 8 have $66 \%$ chances to get LVDD Grade 1 without significant $P$ value of 0.66 . Male patients with $\mathrm{HbA} 1 \mathrm{c}$ of 8 to 10 have $117 \%$ chances to get LVDD grade 1 without significant $P$ value of 0.79 .

Patents with age between 31 to 40 have $28 \%$ chances to get LVDD with significant $P$ value of 0.04 . Patients with age between 31 to 40 have $45 \%$ chances to get LVDD without significant $P$ value of 0.142 .

Abay Kumar Chaudhary et al[9] in their study of 100 asymptomatic subjects found the prevalence of diastolic dysfunction in asymptomatic newly diagnosed Type 2 diabetics as $41 \% .{ }^{[12]}$ Mean of HbA1C (\%) was found higher in group with LVDD $(7.67 \pm 0.90)$ as compared to group without LVDD (7.24 \pm 0.64$)$. This concludes that HbA1C is strongly associated with presence of LVDD ( $\mathrm{p}=0.0057)$. Mean FBS found higher in LVDD group $(189.80 \pm 30.90)$ as compared to LVDD negative group $(179 \pm 29.80)$. Age of the patients was very significantly associated with incidence of LVDD $(\mathrm{p}=0.0012)$, meaning that older the age at the time of diagnosis higher the incidence of LVDD.

Sanjeev Kumar et al[12] in their study of 100 asymptomatic subjects found the prevalence of diastolic dysfunction in asymptomatic newly diagnosed Type 2 diabetics as $42 \%$. Mean of HbA1C (\%) was found higher in group with LVDD (7.69 \pm 1.01$)$ as compared to group without LVDD (7.26 \pm 0.74$)$. This concludes that HbA1C is strongly associated with presence of LVDD ( $\mathrm{p}=0.0157)$. Mean FBS found higher in LVDD group (192.05 \pm 29.80$)$ as compared to LVDD negative group (173.67 \pm 27.71$)$. Age of the patients was very significantly associated with incidence of LVDD ( $\mathrm{p}=0.0012)$, meaning that older the age at the time of diagnosis higher the incidence of LVDD.

Compared to other studies, our study significantly correlated with elevated $\mathrm{HbA1C}$ and elevated FBS to LVDD, whereas age and gender has no statistical significance.[13][14][15]

\section{CONCLUSIONS}

- $\quad$ One-fifth to one-third of patients will develop LVDD in diabetic patients.

- Patients with HBA1C 8 to 10 have double the chances to develop LVDD than with HbA1c 6.5 to 8.

- Patients with HBA1C more than 10 have five times the chances to develop LVDD than with HbA1c 6.5 to 8.

- $\quad$ Patients with HBA1C more than 10 have three times the chances to develop LVDD than with HbA1c 8 to10.

- One-fourth to one-half of diabetic patients will develop LVDD grade 1 in diabetic patients.

- Patients with HBA1C 8 to 10 have double the chances to develop LVDD grade 1 than with HbA1c 6.5 to 8.
- Patients with HBA1C more than 10 have four times the chances to develop LVDD grade 1 than with HbA1c 6.5 to 8 .

- Patients with HBA1C more than 10 have two times the chances to develop LVDD than with HbA1c 8 to10.

- $\quad$ Older the diabetics, more chances of getting LVDD.

- Age group between 50 to 60 years have 4 times and 2 times more chances to get LVDD when compared with age group 40 to 50 and 31 to 40 years respectively.

- $\quad$ Age group between 50 to 60 years have 2 times and 1.25 times more chances to get LVDD grade 1 when compared with age group 40 to 50 and 31 to 40 years respectively.

\section{REFERENCES}

1. Anjana RM, Pradeepa R, Deepa M, et al. Prevalence of diabetes and pre-diabetes in rural and urban India: phase 1 results of the Indian council of medical researchIndia DIABetes (INDIAB) study. Diabetologia 2011;54(12):3022-7.

2. Isaaz $\mathrm{K}$, Thompson $\mathrm{A}$, Ethevenot $\mathrm{G}$, et al. Doppler echocardiographic measurement of low velocity motion of the left ventricular posterior wall. Am J Cardiol 1989;64(1):66-75.

3. Rubler S, Dlugash J, Yuceoglu YZ, et al. New type of cardiomyopathy associated with diabetic glomerulosclerosis. Am J Cardiol 1972;30(6):595-602.

4. Cosson S, Kevorkian JP. Left ventricular diastolic dysfunction: an early sign of diabetic cardiomyopathy. Diabetes Metab 2003;29(5):455-66.

5. Von Bibra H, Hansen A, Dounis V, et al. Augmented metabolic control improves myocardial diastolic function and perfusion in patients with non-insulin dependent diabetes. Heart 2004;90:1483-4.

6. Aneja A, Tang WHW, Bansilal S, et al. Diabetic cardiomyopathy: insights into pathogenesis diagnostic challenges and therapeutic options. The American Journal of Medicine 2008;121(9):748-57.

7. Lopaschuk GD. Metabolic abnormalities in the diabetic heart. Heart Fail Rev 2002;7:149-59.

8. Orea-Tejeda A, Colin-Ramirez E, Castillo-Martinez L, et al. Aldosterone receptor antagonists induce favourable cardiac remodeling in diastolic heart failure patients. Rev Invest Clin 2007;59(2):103-7.

9. Chaudhary AK, Aneja GK, Shukla S, et al. Study on diastolic dysfunction in newly diagnosed type 2 diabetes mellitus and its correlation with glycosylated haemoglobin (HbA1C). Journal of Clinical and Diagnostic Research 2015;9(8):0C20-0C22. DOI: $10.7860 / J C D R / 2015 / 13348.6376$.

10. Saadeh B, Jureidini, Cynthia J, et al. Transthoracic Doppler echocardiography of normally originating coronary arteries in children. Journal of the American Society of Echocardiography 1998;11(5):409-20.

11. American diabetes association report of the expert committee on the diagnosis and classification of diabetes mellitus. America: clinical practice recommendation. Diabetes Care 2006;28(Supl 1):S1-S40. 
12. Kumar S, Aneja GK, Trivedi A, et al, Glycosylated haemoglobin $(\mathrm{HbA1c})$ is a reliable predictor of left ventricular hypertrophy (LVH) and left ventricular diastolic dysfunction (LVDD) in newly diagnosed type 2 diabetic patients of western Uttar Pradesh. International Journal of Scientific and Research Publications 2014;4(12):ISSN 2250-3153.

13. Patil VC, Patil HV, Shah KB, et al. Diastolic function in asymptomatic type 2 diabetes mellitus with normal systolic function. J Cardiovascular Dis Res 2011;2(4):213-22.
14. Shrestha NR, Sharma SK, Karki P, et al. Echo evaluation of diastolic function in asymptomatic type 2 diabetes: a cross sectional study. Journal Nepal Medical Association 2009;48(173):20-3.

15. Mishra R, Das JP. Endomyocardial biopsy in diabetes mellitus. Ind Heart J 1981;33-156. 